\title{
Using the SERVQUAL model to evaluate the quality of services for a farm school store
}

\author{
Michael C. Handrinos \\ Centre for Business in Society \\ Coventry University, UK \\ E-mail:michael@handrinos.eu \\ Dimitrios Folinas \\ Department of Logistics, ATEI Thessaloniki \\ Thessaloniki, Greece \\ E-mail:dfolinas@gmail.com \\ Konstantinos Rotsios \\ Perrotis College \\ The American Farm School of Thessaloniki \\ E-mail: Greece-krotsi@afs.edu.gr
}

Received: 31.01.2014 / Revised: 30.03.2015 / Accepted: 14.04. 2015 / Published online: 30.04.2015

\begin{abstract}
The main objective of this paper is to present and analyse the findings of research which aims to measure the services that a locally-based SME (Small-Medium Enterprise) campus store of a farm school provides to its customers. The examined start-up store is operated by the College students in the context of their entrepreneurship, business and marketing classes. After one year of operation students decided to evaluate the quality of the store's services and measure the customers' satisfaction by applying the well-known SERVQUAL model. The deployment of the model revealed at first the importance of the store know-how to measure services from the consumers' perspective so as to better understand their needs. Secondly, the findings of the research highlighted 'Security', 'Reliability' and 'Empathy' as the most significant dimensions. The findings of this research can help small and medium enterprises to improve the services they provide to their customers by focusing on these three important dimensions.
\end{abstract}

JEL classification: M300, M310, M390, M000

Keywords: Quality of services, SME store, SERVQUAL, farm school, service provision improvement

\section{INTRODUCTION}

In recent years several models have been applied for evaluating the quality of services provided by companies. One popular approach has been the analysis of gaps (Gaps Analysis), which simply 'counts' the distance between the desired level of provided services that customers expect and 
what they ultimately receive. Based on that model Parasuraman, Zeithaml and Berry (1985 and 1990), presented the SERVQUAL model (abbreviation of the words Service and Quality) for measuring the quality of services. In particular, this model is a gauge of how customers perceive a company's quality of service when they receive it.

This measurement is achieved through a comparison between customers' expectations for how they should be provided a service and what they ultimately obtain. Usually, for the description of the five determinants of the model twenty-two variables are used and the respondents are asked to state, usually on a five-class scale from 'Not Important' (1) to 'Very Important' (5), what they are expecting from a service and how that service is perceived. Based on the variations between the expectations and the experiences of customers for the quality of a service, for these twentytwo variables, a final score is then calculated for the quality of service.

The SERVQUAL model has been characterized by its creators as a simple and comprehensive multi-dimensional measuring scale that has good reliability and validity in its results. The authors argue that it can be applied to a large and diverse number of services and commercial enterprises.

At the same time this model has been criticized by some academics and practitioners (Cronin and Taylor, 1992; Babakus and Boller, 1992; Brown et al., 1993; Rust and Oliver, 1994; Dabholkar, Thorpe and Rentz, 1996). In particular, when the SERVQUAL model is used in various business sectors such as hospitals, fast-food companies and cleaners, its results showed that there may be a span of one to eight dimensions of service, depending on the type of business or industry considered. This indicates that the SERVQUAL model may not always be applicable to companies of different sectors in the same manner. Nevertheless, one could argue that as expectations and perceptions of customers are very important to assess the quality of services, the SERVQUAL model can be used to measure how customers perceive the quality of those services.

The main theme of this work will be to determine the level of service quality provided to its customers by the Perrotis College-American Farm School (AFS) Campus Store (known as the AFS Campus Store). For this reason, a number of its customers were interviewed using a questionnaire which was based on the SERVQUAL model. Research focused on investigating how customers evaluated the services they received. The sample was 84 customers that were given the SERVQUAL questionnaire.

\section{LITERATURE REVIEW}

Many studies have been focused on the deployment of the SERVQUAL model into key business sectors during the last decade. SERVQUAL seems to be a trustworthy and reliable tool for decision even today. Recent studies in the health (Ajam, 2014; Khamis and Njau, 2014; Papanikolaou and Zygiaris, 2014; Wongrukmit, P. and Thawesaengskulthai, N., 2014; Anbari, Mohammadi and Taheri, 2014), education (Mansori, Vaz and Ismail, 2014; Zareinejad, 2014; May and Viljoen, 2014; van Schalkwyk and Steenkamp, 2014), and banking (Panda, and Kondasani, 2014; Ali et. al, 2014; Choudhury, 2014; Ryglová, Vajčnerová and Šácha, 2013) sectors confirm this.

On the contrary, limited research efforts are concentrated on measuring the quality of services in the agribusiness sector. In general, von Freymann and Cuffe (2010) suggested that store pricing, store formats, and shopping enjoyment may mitigate ongoing choice.

It is widely accepted that quality means different things to different people. In recent years, a lot of attention has been given to service quality and the ways consumer satisfaction and perceived quality of services can be measured. Many models on service quality have been developed and proposed by researchers.

As Grönroos (1984) suggests, it is important to understand how consumers perceive the quality of services in order to successfully design advertising and marketing strategies. Service 
companies should strive to minimize the gap between the expected service and the perceived service. According to the same researcher, functional quality is a very important component of the perceived service. Functional quality refers to "how" the consumer receives the service whereas "technical quality" refers to "what" the consumer receives.

Brogowicz et al. (1990) have proposed another service quality model with three distinct components: a) company image, b) external influences and c) traditional marketing activities which influence the technical as well as the functional service quality expectations. In addition, Haywood-Farmer's (1988) model on service quality includes physical facilities, processes and procedures, the personal behaviour of the service providers as well as their professional judgment.

According to the findings of Spreng and Mackoy (1996), service quality and satisfaction are distinct. Meeting customers' expectations is not enough; what matters is meeting their desires.

The findings should encourage service-focused small businesses not currently doing so to consider putting quality measurements in place to guide the satisfaction-revenue connection. In specific sectors a small number of research efforts have been found (Table 1):

Table 1

\begin{tabular}{|c|c|c|c|}
\hline Authors & Year & Business Domain & Findings \\
\hline $\begin{array}{l}\text { Evanschitzky, } \\
\text { Iyer and } \\
\text { Caemmerer }\end{array}$ & 2008 & $\begin{array}{l}\text { Agribusiness / } \\
\text { Retail }\end{array}$ & $\begin{array}{l}\text { - Consumer satisfaction with retail stores has } 6 \text { key dimensions } \\
\text { - The dimensions of retail satisfaction have a greater effect on } \\
\text { overall satisfaction than SERVQUAL dimensions }\end{array}$ \\
\hline $\begin{array}{l}\text { Wilson, Hall } \\
\text { and Fields }\end{array}$ & 2011 & $\begin{array}{l}\text { Agribusiness / } \\
\text { Local farm } \\
\text { cooperative } \\
\text { stores }\end{array}$ & $\begin{array}{l}\text { - Younger patrons and homeowners are likely to deem customer } \\
\text { service and personal interaction important } \\
\text { - Customers who consider appearance and accessibility as important } \\
\text { are college graduates and persons dependent on farming } \\
\text { - Older patrons and wildlife enthusiasts are likely to view the } \\
\text { policies and reliability as important factors of service quality }\end{array}$ \\
\hline Tey et al. & 2014 & $\begin{array}{l}\text { Agribusiness / } \\
\text { Hotel, } \\
\text { restaurant, } \\
\text { and catering }\end{array}$ & $\begin{array}{l}\text { - While most service quality factors were insignificant, } \\
\text { "responsiveness" in terms of providing delivery services had } \\
\text { a statistically significant positive impact on HORECA's contractual } \\
\text { arrangement with their current suppliers } \\
\text { - These findings imply that the service quality is being seen as } \\
\text { a supplement; economic factors (e.g., prices and their stability, } \\
\text { credit term) are likely to be the key drivers affecting buyer-seller } \\
\text { relationships }\end{array}$ \\
\hline
\end{tabular}

Our work marks a departure from this literature by assessing the SERVQUAL model to evaluate the quality of services of a store. It is a locally-based SME campus store of a farm school providing food products and specific services to its customers. The key research hypothesis is: " $\mathrm{H}_{1}$ : For an SME campus store the 'Security' and 'Empathy' dimensions are the key contributors to the quality evaluation of the provided services".

\section{RESEARCH METHODOLOGY, PLANNING AND FINDINGS}

The purpose of this study is to measure the quality of the in-store services provided by the AFS Campus Store. In order to collect the required data a questionnaire was developed based on the SERVQUAL model, which refers to the evaluation of the quality of service. The questionnaire includes a total of eighty (80) questions; out of these, seventy-seven (77) are closed-ended 
while three (3) are open-ended. This way our questionnaire could be completed with ease and in a speedy manner by the respondents and at the same time it could provide all the necessary information to conduct our research. We had also provided instructions for the completion of the questionnaire as it was handed by trained people who were there to address any possible queries by the respondents.

During the design of this questionnaire an appropriate and targeted structure was considered in order to make it as effective as possible. Each question is aimed at a specific purpose and can be understood and answered by all respondents. The questions are phrased so as not to guide their responses while, deliberately, there are frequent filter questions to confirm that the respondent answered with the greatest possible honesty. Finally, the structure of the questionnaire is set in such a manner as not to induce any fatigue in the respondent; although one could argue that its size is somewhat long, respondents did not seem to be bothered about that.

The questionnaires were handed out to the participants during their visit to the AFS Campus Store, where they were given instructions on how to complete it. The period of handing them out was from $15^{\text {th }}$ December 2013 until $15^{\text {th }}$ February 2014. Finally, the processing of the completed questionnaires followed, with the help of statistical programs along with a graphical display of each question.

Using a mixed sampling method by combining the convenience sampling during the first month of our survey (15-12-2013 to 15-1-2014) in which the sample was selected in a prism of convenience and the judgment sampling in which during the second month (15-1-2014 to 15-2-2014) we selected the sample based on our judgment (trying to be consistent in terms of gender and age), we collected 168 questionnaires, which can be considered as adequate to achieve a random sample and extract reliable findings considering that the average number of customers per month is approximately 250. The Cronbach's Alpha is 0.802 determining the satisfactory reliability.

The questions of the questionnaire are grouped into six (6) separate sections for greater ease of completion by the respondents. The first section contains general demographic information about the respondent in order for us to acquire knowledge of each individual's profile. According to the results, the demographic profile of the respondents is described as follows: the majority of the respondents were females (75.6\%), between 25-44 years old (almost 70\%), who live in the area of Thessaloniki (75\%) in Greece. They learned about the AFS Campus Store by word of mouth $(65 \%)$ and from articles - periodicals (almost 22\%).

In the second section respondents are asked to rate, on a five-point scale from 'Very low' (1) to 'Very important' (5), the significance of each of the five dimensions of the SERVQUAL model. The results are presented in Table 2 .

Table 2

Significance of 5 dimensions

\begin{tabular}{lcccccc} 
& \multicolumn{5}{c}{ Frequencies (Percentage \%) } & Mean \\
& Very low & Low & Medium & High & Very high \\
Reliability & $1(1.2 \%)$ & $0(0 \%)$ & $25(29.8 \%)$ & $30(35.7 \%)$ & $28(33.3 \%)$ & 4.00 \\
Responsibility & $1(1.2 \%)$ & $3(3.6 \%)$ & $28(33.3 \%)$ & $39(46.1 \%)$ & $12(14.3 \%)$ & 3.70 \\
Security & $0(0 \%)$ & $3(3.6 \%)$ & $12(14.3 \%)$ & $21(25.0 \%)$ & $47(56.0 \%)$ & 4.35 \\
Empathy & $0(0 \%)$ & $4(4.8 \%)$ & $16(19.0 \%)$ & $40(47.6 \%)$ & $23(27.4 \%)$ & 3.99 \\
Tangibility & $0(0 \%)$ & $5(6.0 \%)$ & $30(35.7 \%)$ & $37(44.0 \%)$ & $11(13.1 \%)$ & 3.65
\end{tabular}


According to the findings 'Security' is the most significant dimension ( $\mathrm{M}=4.35, \sim 80 \%$ Very high and High significance). 'Reliability' and 'Empathy' follow ( $\mathrm{M}=4.00, \sim 60 \%$ High and Very high significance; $\mathrm{M}=3.99, \sim 60 \%$ High and Very high significance). 'Responsibility' and 'Tangibility' are less significant $(\mathrm{M}=3.70, \sim 80 \%$ High and Medium significance; $\mathrm{M}=3.65$, $\sim 80 \%$ High and Medium significance). By further examining the mean scores we see that the degrees $(\%)$ of the significance of the dimensions in a descending order are:

- 'Security': $22.90 \%$

- 'Reliability': $20.31 \%$

- 'Empathy': 20.26\%

- 'Responsibility': $18.79 \%$

- 'Tangibility': $18.55 \%$.

Based on the above we can distinguish 3 groups regarding the significance of the dimensions: the first group: 'Security', the second group: 'Reliability' and 'Empathy', the third group: 'Responsibility' and 'Tangibility'.

In the third and fourth sections, respondents are asked to rate, on a five-point scale from 'Very low' (1) to 'Very high' (5), the expected services of the AFS Campus Store as well as the services they perceive. In the following table (Table 3 ) the mean scores of customers' expectations, perceptions and gap scores are presented.

Table 3

Summary of means of customers' expectations, perceptions and gap scores

\begin{tabular}{|c|c|c|c|c|}
\hline Dims & Questions / Statements & $\begin{array}{l}\text { Perceptions } \\
\text { score }\end{array}$ & $\begin{array}{l}\text { Expectations } \\
\text { score }\end{array}$ & $\begin{array}{l}\text { Gap } \\
\text { score }\end{array}$ \\
\hline \multirow{4}{*}{ 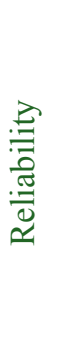 } & $\begin{array}{l}\text { AFS Campus Store keeps its promises when it comes to the provision } \\
\text { of services }\end{array}$ & 3.2500 & 3.2083 & 0.0417 \\
\hline & AFS Campus Store truly cares about solving customer problems & 3.4583 & 3.2083 & 0.2500 \\
\hline & AFS Campus Store provides the service right the first time & 3.5652 & 3.2609 & 0.3043 \\
\hline & AFS Campus Store provides the service at the time promised & 3.4545 & 3.3750 & 0.0795 \\
\hline \multirow{4}{*}{ 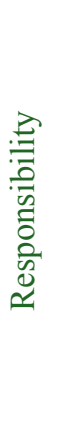 } & $\begin{array}{l}\text { AFS Campus Store can provide a satisfactory service in critical } \\
\text { situations }\end{array}$ & 3.6250 & 3.6087 & 0.0163 \\
\hline & $\begin{array}{l}\text { AFS Campus Store can provide a satisfactory service to the specific } \\
\text { requirements of customers }\end{array}$ & 3.3750 & 3.3333 & 0.0417 \\
\hline & Employees provide direct service to the customer & 3.6667 & 3.7083 & -0.0416 \\
\hline & $\begin{array}{l}\text { Employees inform the customer about the exact time of the service } \\
\text { provision }\end{array}$ & 3.8261 & 3.6522 & 0.1739 \\
\hline \multirow{5}{*}{ 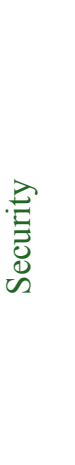 } & The behaviour of employees creates clients' sense of trust & 3.6250 & 3.3750 & 0.2500 \\
\hline & Customers feel safe in their transactions with the AFS Campus Store & 3.4167 & 3.4583 & -0.0416 \\
\hline & Employees are always polite to the customer & 3.5833 & 3.7917 & -0.2084 \\
\hline & $\begin{array}{l}\text { Employees have the appropriate knowledge to answer customers' } \\
\text { questions }\end{array}$ & 3.9565 & 3.6250 & 0.3315 \\
\hline & $\begin{array}{l}\text { Customers can be confident that the service will be provided in } \\
\text { a correct manner }\end{array}$ & 3.8750 & 3.5000 & 0.3750 \\
\hline
\end{tabular}


AFS Campus Store has adapted opening hours to meet all of its customers' needs

\subsection{7}

3.6250

0.0417

Employees show personal interest in each client

3.9167

3.5000

0.4167

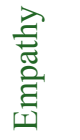

AFS Campus Store aims at providing the maximum possible benefit to the client

3.8261

3.3750

0.4511

Employees understand the individual needs of the customer by paying individual attention

3.8696

3.4783

0.3913

AFS Campus Store effectively manages customers' complaints and problems

3.7826

3.8342

$-0.0516$

AFS Campus Store has modern equipment (vehicles, storage areas, etc.)

3.7500

3.5652

0.1848

氙

AFS Campus Store's physical installations are visually attractive

3.5000

3.5000

0.0000

Employees are always well-dressed and clean

3.6667

3.5000

0.1667

Daily materials (packaging, supplies etc.) that are used in the

provision of services help conclude everyday transactions with AFS Campus Store

According to the results only the following negative gap scores are identified:

- Employees provide direct service to the customer (gap: -0.0416).

- Customers feel safe in their transactions with AFS Campus Store (gap: -0.0416).

- Employees are always polite to the customer (gap: -0.2084).

- AFS Campus Store effectively manages customers' complaints and problems (gap: -0.0516).

The gaps between the existing and anticipated services are calculated by subtracting the value of the existing service from the value of expected service. In general, the observations in Table 3 lead to the conclusion that, with respect to the 'Reliability' and 'Tangibility' dimensions, all perceived services received higher averages than expected, confirming the proper operation of services with respect to these parameters.

As one can observe, the largest positive deviation of satisfaction, which is derived from the actual services offered when compared with the expected ones, appears on the following parameters: 
Table 4

Summary of means of customers' expectations, perceptions and gap scores

Questions / statements

Daily materials (packaging, supplies etc.) that are used in the provision of services help conclude everyday transactions with AFS Campus Store

AFS Campus Store aims at providing the maximum possible benefit to the client

Employees show personal interest in each client

Employees understand the individual needs of the customer by paying individual attention

Customers can be confident that the service will be provided in a correct manner

Employees have the appropriate knowledge to answer customers' questions

AFS Campus Store provides the service right the first time

AFS Campus Store truly cares about solving customer problems

On the contrary, in the 'Security' dimension there are two negative gap scores; in particular, in the 'Customers feel safe in their transactions with the AFS Campus Store' and 'employees are always polite to the customer'. In the other two dimensions ('Responsibility' and 'Empathy'), even if there are negative scores, these are rather low.

We applied the equation $\mathrm{QeS}=\mathrm{w} 1 *(\mathrm{~A} 1+\mathrm{A} 2+\mathrm{A} 3+\mathrm{A} 4)+\mathrm{w} 2 *(\mathrm{~B} 1+\mathrm{B} 2+\mathrm{B} 3+\mathrm{B} 4)+$ $\mathrm{w} 3 *(\mathrm{C} 1+\mathrm{C} 2+\mathrm{C} 3+\mathrm{C} 4+\mathrm{C} 5)+\mathrm{w} 4 *(\mathrm{D} 1+\mathrm{D} 2+\mathrm{D} 3+\mathrm{D} 4+\mathrm{D} 5)+\mathrm{w} 5 *(\mathrm{E} 1+\mathrm{E} 2+\mathrm{E} 3+\mathrm{E} 4)$, which, for the case under investigation, is a modification of the SERVQUAL model where:

- QeS: the overall mark/score of the services' evaluation,

- $\mathrm{w}$ : the percentage degree of the significance of each dimension, as presented above,

- 1,2,3,4,5: the dimensions of the model (Reliability, Responsibility, Security, Empathy and Tangibility respectively),

- A1 to A4: the degree of services' quality assessment that is linked to the parameter of 'Reliability'.

- B1 to B4: the degree of services' quality assessment that is linked to the parameter of 'Responsibility'.

- C1 to C5: the degree of services' quality assessment that is linked to the parameter of 'Security'.

- D1 to D5: the degree of services' quality assessment that is linked to the parameter of 'Empathy', and

- E1 to E4: the degree of services' quality assessment that is linked to the parameter of 'Tangibility'.

Thus, QeS $=22,9 *(0,0417+0,25+0,3043+0,0795)+20,31 *(0,0163+0,0417-0,0416+$ $0,1739)+20,26 *(0,25-0,0416-0,2084+0,3315+0,375)+18,79 *(0,0417+0,4167+0,4511$ $+0,3913-0,0516)+18,55 *(0,1848+0+0,1667+0,4584)$.

We also found out that the overall Quality Score $(\mathrm{QeS})$ is equal to +72.14 . The price index shows that, according to the respondents' replies, there is a very positive discrepancy between the expected and the provided services. Specifically, more than $75 \%$ of the items have positive gap scores. Furthermore, the following figure (Figure 1) depicts that all the dimensions are positively affecting the model. 
Figure 1

Contribution of the dimensions to the QeS

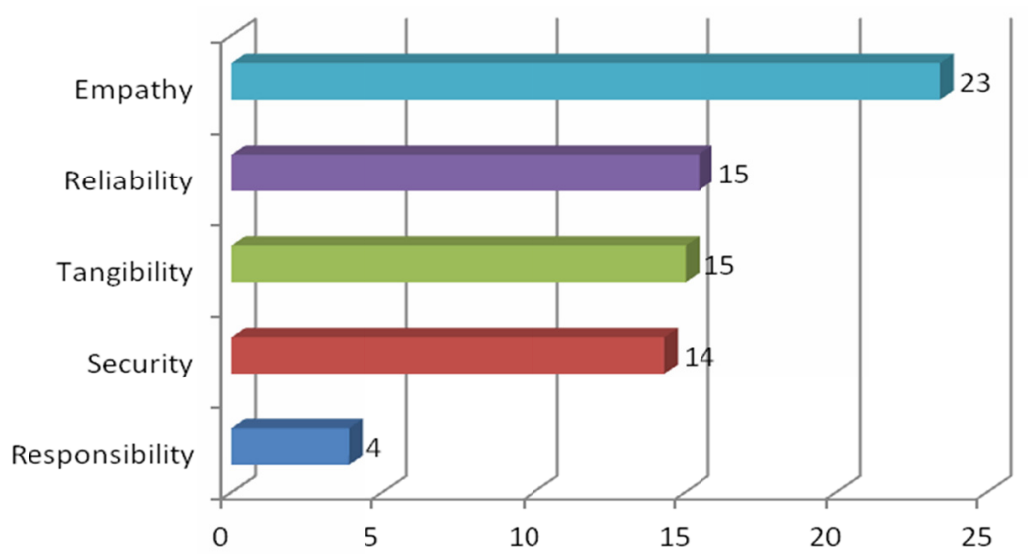

The fifth section contains all the items of every dimension and is intended to evaluate the contribution of each of these items to each dimension (Table 5).

Table 5

Means of the dimensions' items

\begin{tabular}{|c|c|c|}
\hline Dims & Questions / Statements & Mean \\
\hline \multirow{4}{*}{ 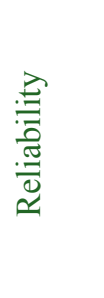 } & AFS Campus Store keeps its promises when it comes to the provision of services & 3,63 \\
\hline & AFS Campus Store truly cares about solving customer problems & 3,59 \\
\hline & AFS Campus Store provides the service right the first time & 3,57 \\
\hline & AFS Campus Store provides the service at the time promised & 3,63 \\
\hline \multirow{4}{*}{ 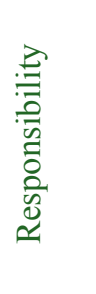 } & AFS Campus Store can provide a satisfactory service in critical situations & 3,48 \\
\hline & AFS Campus Store can provide a satisfactory service to the specific requirements of customers & 3,54 \\
\hline & Employees provide direct service to the customer & 3,83 \\
\hline & Employees inform the customer about the exact time of the service provision & 3,79 \\
\hline \multirow{5}{*}{ 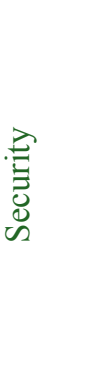 } & The behaviour of employees creates clients' sense of trust & 3,80 \\
\hline & Customers feel safe in their transactions with AFS Campus Store & 3,90 \\
\hline & Employees are always polite to the customer & 3,98 \\
\hline & Employees have the appropriate knowledge to answer customers' questions & 3,87 \\
\hline & Customers can be confident that the service will be provided in a correct manner & 3,98 \\
\hline \multirow{5}{*}{ 志 } & AFS Campus Store has adapted opening hours to meet all of its customers' needs & 3,77 \\
\hline & Employees show personal interest in each client & 3,77 \\
\hline & AFS Campus Store aims at providing the maximum possible benefit to the client & 3,80 \\
\hline & Employees understand the individual needs of the customer by paying individual attention & 3,73 \\
\hline & AFS Campus Store effectively manages customers' complaints and problems & 3,79 \\
\hline
\end{tabular}


AFS Campus Store has modern equipment (vehicles, storage areas, etc.)

AFS Campus Store's physical installations are visually attractive

Daily materials (packaging, supplies etc.) that are used in the provision of services help conclude everyday transactions with AFS Campus Store

Another aspect investigated is the assessment of the importance that respondents were giving on the items of the examined dimensions. The relevant contribution of each dimension is presented in Table 6 .

Table 6

Relevant contribution of each dimension to the total evaluation

\begin{tabular}{lc}
\multicolumn{1}{c}{ Dimension } & Contribution \% \\
Reliability & $18 \%$ \\
Responsibility & $18 \%$ \\
Security & $24 \%$ \\
Empathy & $23 \%$ \\
Tangibility & $18 \%$ \\
\hline
\end{tabular}

The analysis showed that there is a differentiation between the perceptions of respondents about the importance of the dimensions and in the results obtained from the ServQual evaluation. As shown in Figure 2, although the differences are small, respondents felt that 'Reliability', 'Responsibility' and 'Tangibility' were less important than they actually are; conversely, they overestimate the contribution of the 'Security' and 'Empathy' dimensions.

\section{Figure 2}

Differences in the relative contribution between the perception of customers and the ServQual evaluation

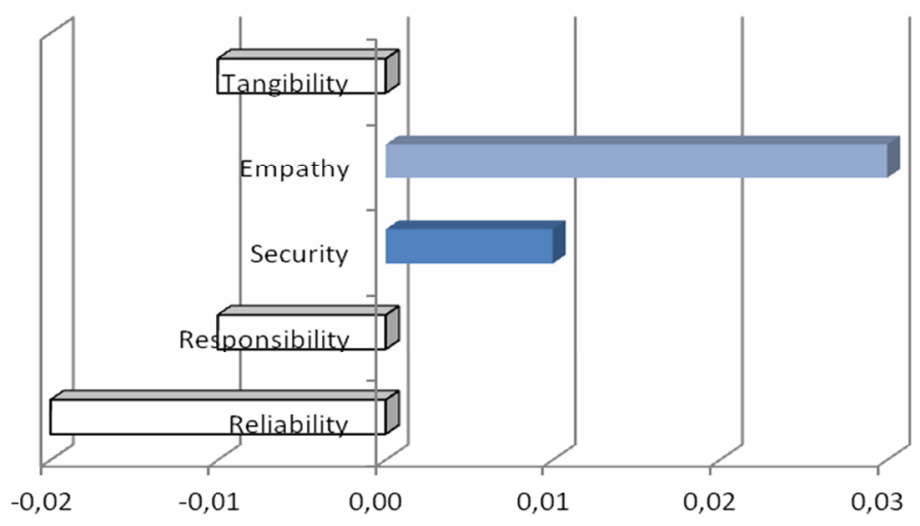

Finally, the sixth section is an attempt by respondents to evaluate the significance of the AFS Campus Store's actions which will further improve the quality of services provided to them in the future. 
Table 7

Significance of the actions of the management of AFS Campus Store

\begin{tabular}{lc}
\multicolumn{1}{c}{ Actions } & Mean \\
\hline Focus on customer needs & 2.43 \\
Focus on staff training & 2.64 \\
Focus on bidirectional communication between the company and customers & 2.65 \\
Flexibility in the execution of services that are based on the needs and problems of customers & 2.65
\end{tabular}

Regarding the significance of the actions of AFS Campus Store that are expected to improve the quality of its services, respondents felt that all the above-mentioned ones are important.

\section{CONCLUSIONS}

Based on the findings of our survey, in this section we discuss the findings by comparing them with similar research efforts and the managerial implications.

\subsection{Discussion of the Findings}

A series of researchers have questioned the reliability and validity of the SERVQUAL scale. Robinson (1999), in his analysis of measuring service quality, believes that "Serious doubt must be raised over the future use of SERVQUAL as a means for measuring service quality. At best it can be argued that SERVQUAL is applicable to contexts close to its original setting. It is questionable whether SERVQUAL is a reliable measure of service quality or, indeed, whether it is measuring service quality at all”. However, and contrary to all opposite claims, SERVQUAL has maintained its position as a pioneering tool used by service providers in the search for consumer data (Jiang et al., 2000; Lam et al. 1997; Newman 2001).

One of the most important and immediate implications in our research is that consumers should not treat SERVQUAL as an "off-the-shelf" measure of perceived service quality. Much refinement is needed for specific companies and industries. As one could suggest, further research in retailing and other service categories is needed to examine the construct validity of SERVQUAL. As Finn and Lamb (1991) argue, questions to be examined could include the following: (1) Are the dimensions of service quality the same regardless of service category? (2) Are the five dimensions of service quality identified by Parasuraman, Berry, and Zeithaml generic? (3) Does the SERVQUAL instrument measure the determinants of perceived service quality in all service industries? The results reported here suggest that the construct validity of SERVQUAL should be examined on an industry by industry basis before it is used to gather consumers' perceptions of service quality.

Our research assumptions are somewhat similar to the one found by Johnston (1995). In his own study he indicated that critical incidents during a service lead to a feeling of satisfaction or dissatisfaction. It is possible, Johnston argued, that the sources of satisfaction and dissatisfaction are indeed things other than critical incidents. Thus, one could suggest that it could be that a service process that is provided just below the satisfaction threshold, giving no critical incidents and thus never crossing this threshold, could lead to an overall feeling of satisfaction. It could be that an overall feeling of satisfaction could have little to do with the service process itself or expectations of it, but in fact be a function of the customer's personal disposition on entering the system. 


\subsection{Managerial Implications}

In order to focus on the actual findings of our research one would have expected that in such a small-sized store customers would usually indicate responsibility and reliability as being the highest options on their list. However, in our instance, we found out that security, reliability along with empathy - were the most important dimensions that AFS Campus Store customers indicated. By further examining the mean scores we found out that the degrees $(\%)$ of the significance of the dimensions in a descending order were:

- 'Security': $22.90 \%$

- 'Reliability': $20.31 \%$

- 'Empathy': 20.26\%

- 'Responsibility': $18.79 \%$

- 'Tangibility': $18.55 \%$.

The overall Quality Score (QeS) was equal to +72.14 and there was a very positive discrepancy between the expected and the provided services. More than $75 \%$ of the items have a positive gap score. Respondents felt that 'Reliability', 'Responsibility' and 'Tangibility' were less important than they actually are; conversely, they overestimate the contribution of the 'Security' and 'Empathy' dimensions.

A number of limitations can be identified in our study. First, the fact that the questionnaires have been collected in a specific time period ( 2 months) which may not give a holistic view of customers' perception. Furthermore, we have to take into account the limitations of the SERVQUAL model (e.g. SERVQUAL is process-oriented: it focuses on the process of service delivery, not on the outcomes of the service encounter, and also the fact that five dimensions are not universal).

The findings of this particular study could help SME-sized companies to focus on specific dimensions/attributes that customers consider as most important: security, reliability and empathy; thus, that way they may seek to improve them by implementing the following actions: keeping promises with regard to the provision of their service; the expression of genuine interest in solving the problems of the customers; providing the appropriate level of service and getting it right from the first time and in the right time.

Finally, in order for a particular company to adjust the level of the offered services in critical situations it should address each customer's specific and unique requirements in a direct manner, and provide information to the customer about the exact time that the service is going to be delivered.

The study of more food stores will be the next steps in order to measure the services that a locally-based SME store provides to its customers. Such an effort could help identify not only more important dimensions of the provided services but also propose specific actions so as to help small and medium enterprises to improve the services they provide to their customers by focusing on these dimensions.

\section{References}

Ajam, M., Sadeghifar, J., Anjomshoa, M., Mahmoudi, S., Honarvar, H. and Mousavi, S.M. (2014) 'Assessing quality of healthcare service by the SERVQUAL model: A case study of a field hospital', Journal of Military Medicine, 15 (4), pp. 273-279.

Ali, S.S., Kaur, R., Pande, M.J.C. and Ahmad, F. (2014) 'Service quality gap approach: A case of Indian customer's satisfaction of private banks', International Journal of Business Excellence, 7 (4), pp. 429-453.

Anbari, Z., Mohammadi, M. and Taheri, M. (2014) 'Measurement of quality of hospital services via SERVQUAL model’, Life Science Journal, 11 (6), pp. 51-56. 
Babakus, E. and Boller, G.W. (1992), ‘An empirical assessment of the SERVQUAL scale', Journal of Business Research, 26 (6), pp. 253-68.

Brogowicz, A.A., Delene, M.M. and Lyth, D.M. (1990) 'A Synthesized Service Quality Model with Managerial Implications’, International Journal of Service Industry Management, 1 (1), pp. 27-45.

Brown, T.J., Churchill, G.A. and Peter, J.P. (1993) 'Research note: improving the measurement of service quality', Journal of Retailing, 69 (1), pp. 126-39.

Choudhury, K. (2014) 'Service Quality and Customers' Complaining Behavior: A Study of the Indian Banking Sector', Services Marketing Quarterly, 35 (2), pp. 123-137.

Cronin, J.J. and Taylor, S.A. 1992, 'Measuring service quality: A re-examination and extension', Journal of Marketing, 56 (3), pp. 55-68.

Dabholkar, P., Thorpe, D.I. and Rentz, J.O. (1996) ‘A Measure of Service Quality for Retail Stores: Scale Development and Validation', Journal of the Academy of Marketing Science, 24 (1), pp.3-16.

Evanschitzky, H., Iyer, G.R., Caemmerer, B. (2008) 'Dimensions of satisfaction in retail settings: A research note', Journal of Relationship Marketing, 7 (3), pp. 275-285.

Finn, D.W. and Lamb, C.W. (1991) 'An Evaluation of the SERVQUAL Scales in a Retailing Setting', Advances in Consumer Research, 18, pp. 483-490.

Grönroos, C. (1984) 'A Service Quality Model and Its Marketing Implications', European Journal of Marketing, 18 (4), pp. 36-44.

Haywood-Farmer, J. (1988) ‘A Conceptual Model of Service Quality’, International Journal of Operations \& Production Management, 8 (6), pp 19-29.

Jiang, J.J., Klein, G. and Crampton, S.M. (2000) 'A Note on SERVQUAL Reliability and Validity in Information Service Quality Assessment', Decision Sciences, Summer, pp. 725-744.

Johnston R. (1995) 'The determinants of service quality: satisfiers and dissatisfiers', International Journal of Service Industry Management, 6 (5), pp. 53-71.

Khamis, K. and Njau, B. (2014) 'Patients' level of satisfaction on quality of health care at Mwananyamala hospital in Dar es Salaam, Tanzania', BMC Health Services Research, 14 (1), 18 September 2014, Article number 400.

Lam, T., Wong, A. and Yeung, S. (1997) 'Measuring Service Quality in Clubs: An Application of the SERVQUAL', Australian Journal of Hospitality Management, 4, pp. 1-8.

Mansori, S., Vaz, A. and Ismail, Z.M.M. (2014) 'Service quality, satisfaction and student loyalty in Malaysian private education’, Asian Social Science, 10 (7), pp. 57-66.

May, C. and Viljoen, P. (2014) 'Service quality at a South African university: An exploratory study', Mediterranean Journal of Social Sciences, 5 (20), pp. 882-887.

Newman, K. (2001) 'Interrogating SERVQUAL: A Critical Assessment of Service Quality Measurement in a High Street Retail Bank', International Journal of Bank Marketing, 19 (3), pp. 126-139.

Panda, R.K. and Kondasani, R.K.R. (2014) 'Assessing customers' perceived service quality in private sector banks in India', Serbian Journal of Management, 9, pp. 91-103.

Papanikolaou, V. and Zygiaris, S. (2014) 'Service quality perceptions in primary health care centres in Greece', Health Expectations, 17 (2), pp. 197-207.

Parasuraman, A., Berry, L.L. and Zeithaml, V.A. (1985) ‘A Conceptual Model of Service Quality and Its Implications for Future Research', Journal of Marketing, 49 (4), pp. 41-50.

Robinson, S. (1999) 'Measuring Service Quality: Current Thinking and Future Requirements', Marketing Intelligence \& Planning, 17, pp. 21-32.

Rust, R.T. and Oliver, R.L. (1994) 'Service Quality: Insights and Managerial Implications from the Frontier', in R.T. Rust and R.L. Oliver (eds.), Service Quality: New Directions in Theory and Practice, Thousand Oaks, CA: Sage Publications.

Ryglová, K., Vajčnerová, I. and Šácha, J. (2013) 'Approaches to quality management in hotel industry', Acta Universitatis Agriculturae et Silviculturae Mendelianae Brunensis, 61 (7), pp. 2693-2699.

Spreng, R.A. and Mackoy, R.D. (1996) 'An Empirical Examination of a Model of Perceived Service Quality and Satisfaction', Journal of Retailing, 72 (2), pp. 201-214.

Tey, Y.S., Brindal, M., Fatimah, M.A., Kusairi, M.N., Ahmad Hanis, I.A. and Suryani, D. (2014) 'The impact of service quality on business commitment in B2B segment of agribusiness: An exploratory study of HORECA sector in Malaysia', International Food Research Journal, 21 (3), pp. 883-889.

Tey, Y.S., Brindal, M., Fatimah, M.A., Kusairi, M.N., Ahmad Hanis, I.A. and Suryani, D. (2014) The impact of service quality on business commitment in B2B segment of agribusiness: An exploratory study of HORECA sector in Malaysia, International Food Research Journal, 21 (3), pp. 883-889.

van Schalkwyk, R.D. and Steenkamp, R.J. (2014) 'Service quality - Cases of private higher education institutions explored', Corporate Ownership and Control, 11 (2), pp. 402-414.

von Freymann, J. and Cuffe, B. (2010) 'Consumer service quality assessments and future revenues in small businesses: A case study’, Services Marketing Quarterly, 31 (4), pp. 381-419. 
Wilson, N., Hall, T. and Fields, D. (2011) 'Source of the Document International' Food and Agribusiness Management Review, 14 (1), pp. 1-22.

Wongrukmit, P. and Thawesaengskulthai, N. (2014) 'Hospital service quality preferences among culture diversity', Total Quality Management and Business Excellence, 25 (7-8), pp. 908-922.

Zareinejad, M., Kaviani, M.A., Esfahani, M.J. and Masoule, F.T. (2014) 'Performance evaluation of services quality in higher education institutions using modified SERVQUAL approach with grey analytic hierarchy process (G-AHP) and multilevel grey evaluation', Decision Science Letters, 3 (2), pp. 143-156.

Zeithaml, V., Parasuraman, A. and Berry, L.L. (1990) Delivering Quality Service; Balancing Customer Perceptions and Expectations, New York: Free Press. 